\title{
Experimental Dynamic Analysis of a Breathing Cracked Rotor
}

\author{
Chao-Zhong Guo ${ }^{1} \cdot \mathrm{Ji}^{-H o n g}$ Yan $^{1} \cdot$ Lawrence A. Bergman $^{2}$
}

Received: 5 December 2016/Revised: 10 May 2017/Accepted: 23 July 2017/Published online: 2 August 2017

(C) The Author(s) 2017. This article is an open access publication

\begin{abstract}
Crack fault diagnostics plays a critical role for rotating machinery in the traditional and Industry 4.0 factory. In this paper, an experiment is set up to study the dynamic response of a rotor with a breathing crack as it passes through its $1 / 2,1 / 3,1 / 4$ and $1 / 5$ subcritical speeds. A cracked shaft is made by applying fatigue loads through a three-point bending apparatus and then placed in a rotor testbed. The vibration signals of the testbed during the coasting-up process are collected. Whirl orbit evolution at these subcritical speed zones is analyzed. The Fourier spectra obtained by FFT are used to investigate the internal frequencies corresponding to the typical orbit characteristics. The results show that the appearance of the inner loops and orientation change of whirl orbits in the experiment are agreed well with the theoretical results obtained previously. The presence of higher frequencies $2 \mathrm{X}, 3 \mathrm{X}, 4 \mathrm{X}$ and $5 \mathrm{X}$ in Fourier spectra reveals the causes of subharmonic resonances at these subcritical speed zones. The experimental investigation is more systematic and thorough than previously reported in the literature. The unique dynamic behavior of the orbits and frequency spectra are feasible features for practical crack diagnosis. This paper provides a critical technology support for the self-aware health management of rotating machinery in the Industry 4.0 factory.
\end{abstract}

Supported by National Natural Science Foundation of China (Grant No. 51505099).

Ji-Hong Yan jyan@hit.edu.cn

1 School of Mechatronics Engineering, Harbin Institute of Technology, Harbin 150001, China

2 Department of Aerospace Engineering, University of Illinois at Urbana-Champaign, Urbana 61801, USA
Keywords Industry 4.0 - Fault diagnosis - Cracked rotor · FFT spectra

\section{Introduction}

The recently emerged conception "Industry 4.0 " is one of the most popular manufacturing topics among the industry and academia in the world which was first announced at the 2013 Hannover Fair [1]. Similar strategies have also been proposed by other main industrial countries, such as "Industrial Internet" by US and "Made in China 2025" by China [2]. Focusing on cyber-physical systems (CPS), Industry 4.0 is regarded as the next-generation production framework for the fourth industrial revolution [3] and promises to create the smart factory [4]. As one of the main components of Industry 4.0, the smart factory will involve a new integrative system, where not only all manufacturing resources (sensors, actuators, machines, robots, etc.) are connected and exchange information automatically, but also the factory will become conscious and intelligent enough to predict and maintain the machines; and intelligent enough to predict and maintain the machines [5, 6]. Many new technologies and methodologies have been developed in the related fields to promote the revolution, such as the crowsdsourcing based new production development in manufacturing SMEs [7], Quality assurance system [8], standardization towards Industry 4.0 [9], wireless device connection [10]. Because of high connection, the health condition of a single machine has greater influence on the factory operation than ever before. Online fault diagnostics and prognostics provide critical health information for the self-aware building and decision making which will play an important role in the Industry 4.0 factory [11]. 
Rotating machines are extensively used in industry, such as the compressors, rotors in manufacturing machines, steam and gas turbines, generators, and pumps [12-14]. Fatigue cracking of rotor shafts is an important phenomenon that can lead to severe damage and great economic loss if not detected in time, especially for the highly connected and automatic production system in the Industry 4.0 factory. The CPS provides great opportunity to perform online crack detection based on the broad implement of sensors, data acquisition systems, computer networks and cloud computing systems together with the rotor dynamic theory so that the sudden breakdown of production lines due to the cracked shafts can be avoided.

It has been shown in the literature that the presence of a crack introduces additional flexibility to the shaft, which reduces its overall stiffness and generates complex orbits and super-harmonic frequency components [15, 16]. The dynamic analysis of cracked rotor systems has been intensively studied by many researchers [17-23]. Sinou, et al. [17] evaluated the dynamic response of the rotor with a breathing crack by expanding the changing stiffness of the crack in a truncated Fourier series and using the Harmonic Balance Method. The orbits during transient operation at the critical speed and at half of the critical speed were considered to be the unique characteristics of the cracked rotor system. Babu, et al. [18] used the HilbertHuang transform to study the transient response of a cracked rotor passing through its critical speed. A frequency fluctuation was observed at the sub-critical speed. Al-Shudeifat [19] and Silani, et al. [20] used finite element models to establish the dynamic equations of the cracked rotor system. The whirl orbit and the shifts in the critical and subcritical speeds were studied. Shravankumar, et al. [21] utilized a full-spectrum method obtained by complex Fast Fourier transform to estimate the force and displacement coefficients for crack identification. The typical orbits and the frequency spectrum at the sub-critical speed were investigated. Lu, et al. [22] studied the nonlinear response characteristics of a breathing transverse crack rotor. The results indicate that the transverse crack causes super-harmonic resonance peaks at the second, third and fourth subcritical speeds. In an earlier paper by a subset of the authors [23], a new breathing function was proposed and the empirical mode decomposition was used to study the high-order frequency variation of a Jeffcott rotor with a transvers breathing crack. The typical whirl orbits during passage through the $1 / 3$ and $1 / 2$ subcritical speeds were observed. Based on aforementioned literature and other references therein, it can be concluded that analyzing unique characteristics of the dynamic response is a feasible and widely used method for crack detection.

However, although many papers have been published in this area, only a few employ actual results from laboratory experiments [24]. Darpe, et al. [25] verified theoretical findings through experiments with a fatigue crack rotor. The orbits and FFT spectra during the rotor passage through the $1 / 3$ and $1 / 2$ critical speeds consistently matched the theoretical findings. Later, Zhou, et al. [26] and Ren, et al. [27] adopted a similar method to further examine fatigue in cracked rotors. Compared with real fatigue cracks, the open crack is easier to implement in the experiment. Dong, et al. [28], Lin, et al. [29], and Mohammed, et al. [30] used a wire cutter machine to generate slits with different depths in the rotor which were generally viewed as open cracks.

In this research, the dynamic response of a breathing cracked rotor was studied experimentally. A real fatigue crack was induced using a three-point bending machine. The unique orbit evolution was compared with the theoretical findings given in Ref. [19], and the frequency spectra obtained by FFT method were analyzed as well. This work presents an effective crack detection method based on the dynamic response for the online diagnosis of rotor systems in the future smart factory.

\section{Theoretical Analysis of the Cracked Rotor System}

In Ref. [23], a Jeffcott rotor model was established, and a breathing function was synthesized using Fourier series to approximate the actual breathing process. The breathing of the crack during the shaft rotation can be described as shown Figure 1. When open, the crack causes a reduction in bending stiffness of the shaft, while when fully closed (see Figure 1(f), the bending stiffness is equal to that of the uncracked rotor. Therefore, the breathing phenomenon leads to a time-varying stiffness matrix in the governing equations of the cracked rotor system. The governing equations of the cracked rotor system are given by

$$
\left\{\begin{array}{l}
m \ddot{u}+c \dot{u}+k_{1}(t) u+k_{12}(t) v=m_{e d} \Omega^{2} \sin (\Omega t+\beta), \\
m \ddot{v}+c \dot{v}+k_{21}(t) u+k_{2}(t) v=m_{e d} \Omega^{2} \cos (\Omega t+\beta)-m g,
\end{array}\right.
$$

where $k_{1}(t), k_{2}(t)$ are the instantaneous stiffnesses respectively in the horizontal and vertical directions, and $k_{12}(t)$, $k_{21}(t)$ are the cross-coupling stiffnesses. The definitions of other parameters can be found in Ref. [23].

The governing equations are solved for relative crack depth of $\mu=0.2$, and the whirl orbits during passage through the $1 / 3$ and $1 / 2$ subcritical speeds are shown in Figure 2. It can be seen that near the $1 / 3$ subcritical speed two inner loops appear (see Figure 2(a)) and get larger as the rotating speed approaches the $1 / 3$ subcritical speed in 


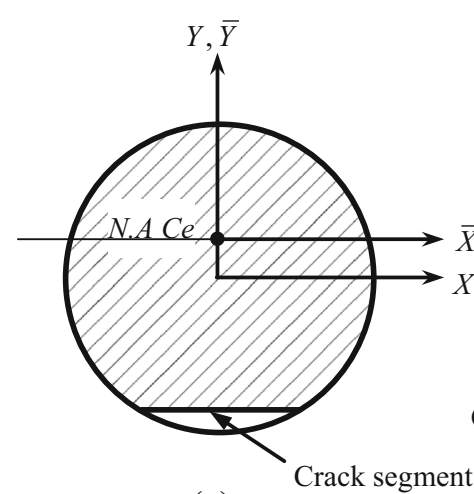

(a)

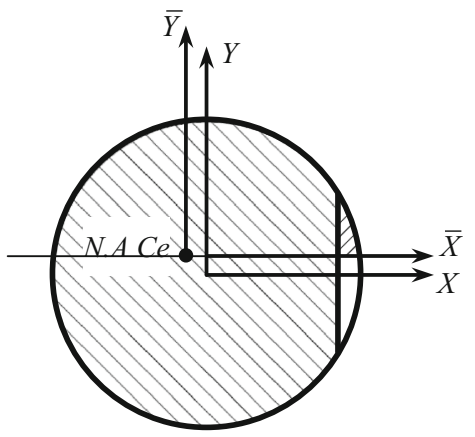

(d)

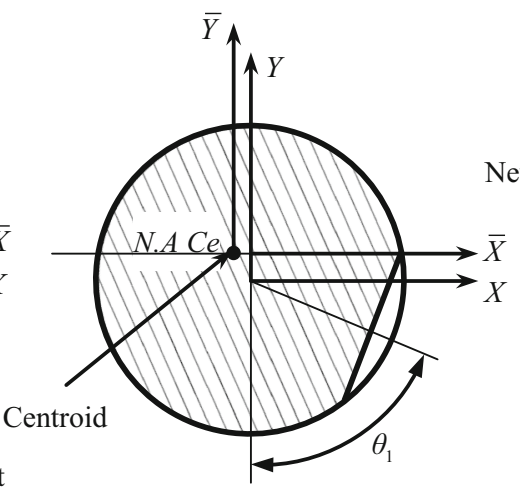

(b)

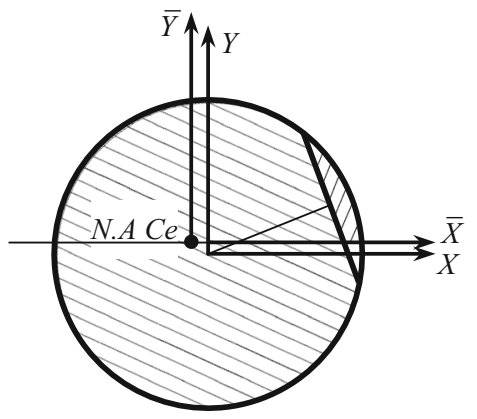

(e)

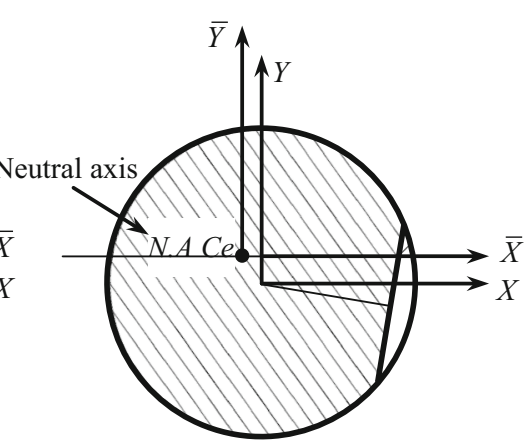

(c)

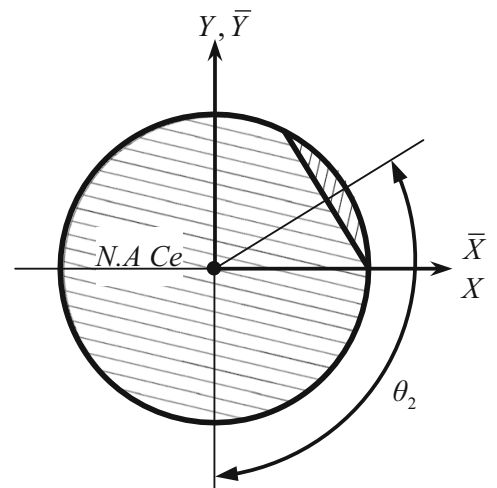

(f)

Figure 1 States of the breathing crack during shaft rotation [23]

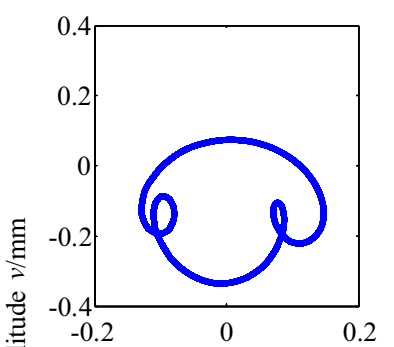

(a) $\Omega=820 \mathrm{r} / \mathrm{min}$

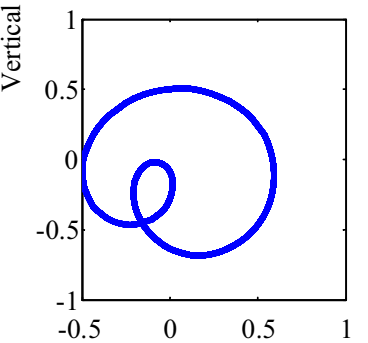

(e) $\Omega=1250 \mathrm{r} / \mathrm{min}$

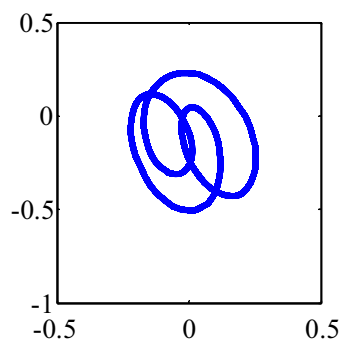

(b) $\Omega=840 \mathrm{r} / \mathrm{min}$

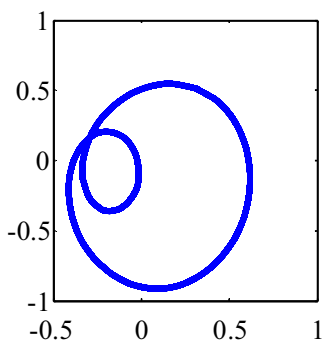

(f) $\Omega=1270 \mathrm{r} / \mathrm{min}$

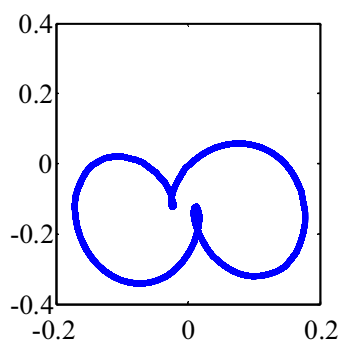

(c) $\Omega=860 \mathrm{r} / \mathrm{min}$

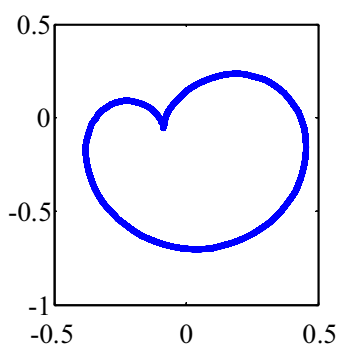

(g) $\Omega=1290 \mathrm{r} / \mathrm{min}$

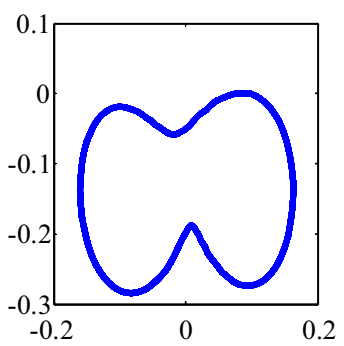

(d) $\Omega=880 \mathrm{r} / \mathrm{min}$

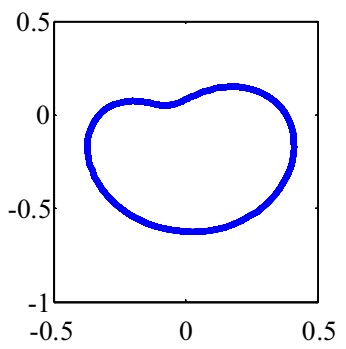

(h) $\Omega=1310 \mathrm{r} / \mathrm{min}$

Horizental amplitude $u / \mathrm{mm}$

Figure 2 Whirl orbits of the cracked rotor during passage through the $1 / 3$ and $1 / 2$ subcritical speeds for $\mu=0.2$ [23]

Figure 2(b). Then, as the speed further increases, the inner loops become smaller and finally disappear, Figure 2(d). Similarly, near the $1 / 2$ subcritical speed, one inner loop appears and evolves similarly, shown in Figures 2(e)-2(h).
In addition, in the $1 / 3$ subcritical speed zone, the loops appear and disappear at about $\pi / \pi 2.2 \mathrm{rad}$, while in the $1 / 2$ subcritical speed zone, the loops appear at about $\pi \mathrm{rad}$. These results are quite consistent with the results of Refs. 
$[19,25]$, which leads us to consider the orbits as a reasonable feature for crack identification.

\section{Experimental Validation}

An experiment is set up on a rotor test rig which consisted of a real fatigue shaft supported by a pair of identical ball bearings, a disk, two eddy current sensors and a DC motor as shown in Figure 3. The mass of the disk is $500 \mathrm{~g}$. The diameter of the shaft is $10 \mathrm{~mm}$, and the span between the two bearings is $400 \mathrm{~mm}$.

A fatigue crack is generated on the shaft transversely by using a three-point-bending machine. Firstly, a slot is made by a wire-electrode cutting machine near the middle of the effective supported span as the initial fault. Then the shaft is placed in the three-point-bending machine and subjected to cyclic loading in a sinusoidal form at the nearby of the precut slot. After about 5000 cycles, the crack propagates to a depth of about $3.2 \mathrm{~mm}$. The displacement of the center of the cracked section is measured by the eddy current sensors implemented in both the horizontal and vertical directions. A speed controller is used to adjust the rotation speed. The vibration signal is collected by a PXI data acquisition box produced by the National Instruments Company.

In order to verify the typical whirl orbits during passage through the subcritical speeds, a coast up and rundown process was performed. The first critical speed of the cracked rotor system was found at about $3300 \mathrm{r} / \mathrm{min}$. The

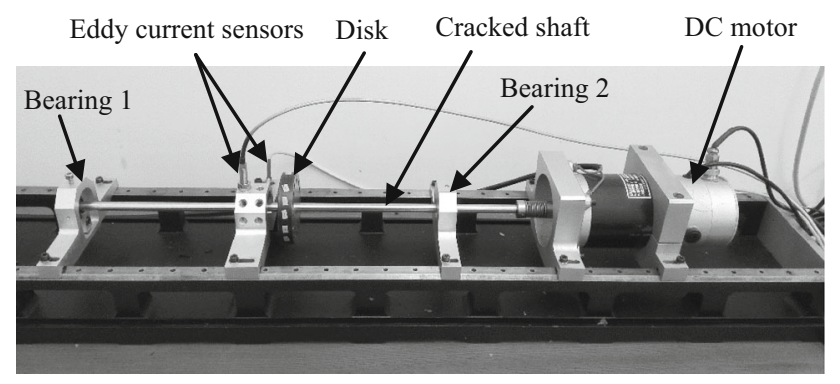

Figure 3 Rotor test rig

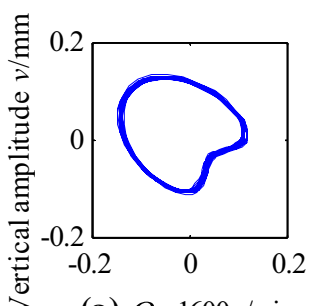

(a) $\Omega=1600 \mathrm{r} / \mathrm{min}$

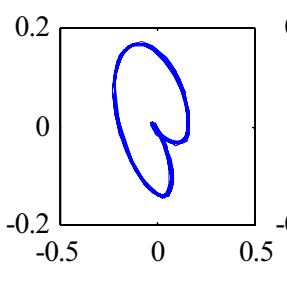

(b) $\Omega=1660 \mathrm{r} / \mathrm{min}$

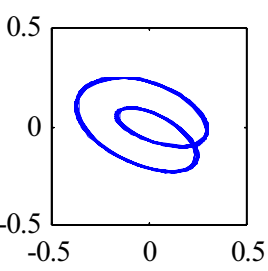

(c) $\Omega=1680 \mathrm{r} / \mathrm{min}$

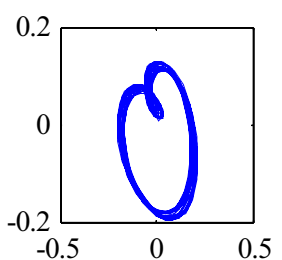

(d) $\Omega=1740 \mathrm{r} / \mathrm{min}$

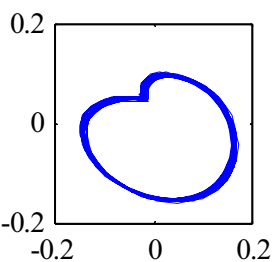

(e) $\Omega=1770 \mathrm{r} / \mathrm{min}$

Horizontal amplitude $u / \mathrm{mm}$

Figure 4 Experimental whirl orbits of the cracked rotor during passage through the $1 / 2$ subcritical speed 


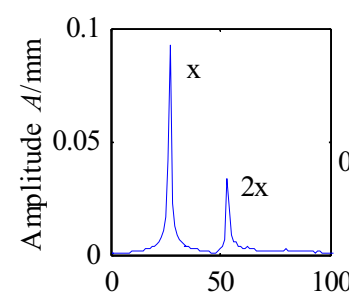

(a) $\Omega=1600 \mathrm{r} / \mathrm{min}$

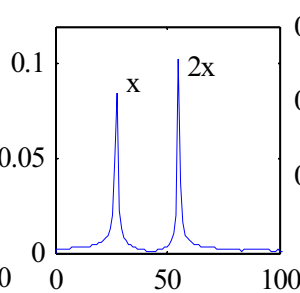

(b) $\Omega=1660 \mathrm{r} / \mathrm{min}$

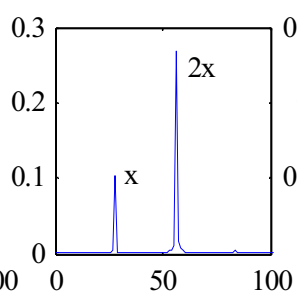

(c) $\Omega=1680 \mathrm{r} / \mathrm{min}$ Frequency $f / \mathrm{Hz}$

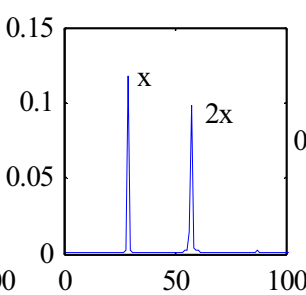

(d) $\Omega=1740 \mathrm{r} / \mathrm{min}$

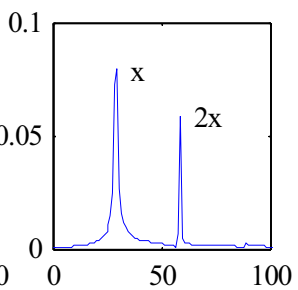

(e) $\Omega=1770 \mathrm{r} / \mathrm{min}$

Figure 5 Frequency spectra of response in the horizontal direction during passage through the 1/2 subcritical speed

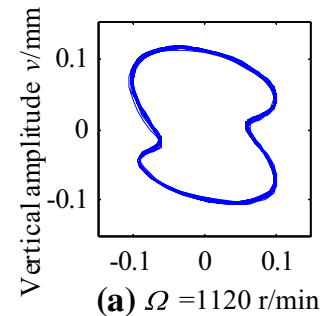

(a) $\Omega=1120 \mathrm{r} / \mathrm{min}$

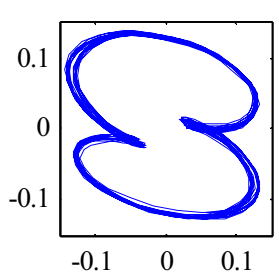

(b) $\Omega=1125 \mathrm{r} / \mathrm{min}$

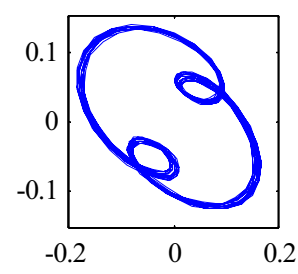

(c) $\Omega=1140 \mathrm{r} / \mathrm{min}$

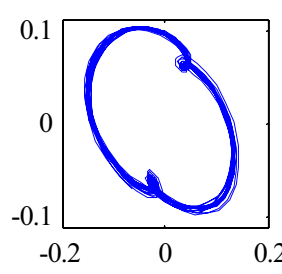

(d) $\Omega=1150 \mathrm{r} / \mathrm{min}$

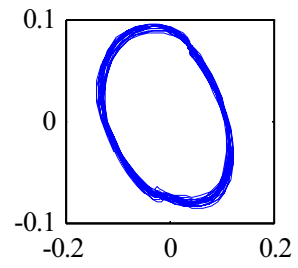

(e) $\Omega=1160 \mathrm{r} / \mathrm{min}$

Horizontal amplitude $u / \mathrm{mm}$

Figure 6 Experimental whirl orbits of the cracked rotor during passage through the $1 / 3$ subcritical speed

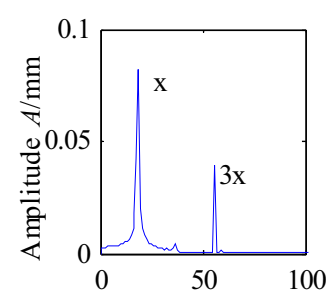

(a) $\Omega=1120 \mathrm{r} / \mathrm{min}$

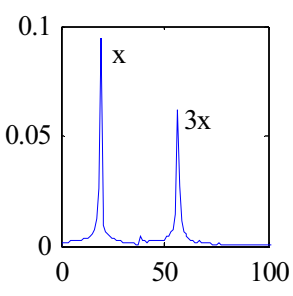

(b) $\Omega=1125 \mathrm{r} / \mathrm{min}$

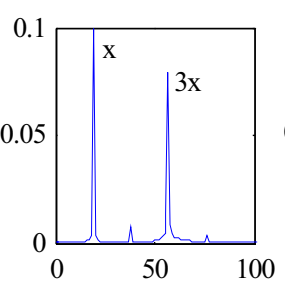

(c) $\Omega=1140 \mathrm{r} / \mathrm{min}$ Frequency $f / \mathrm{Hz}$

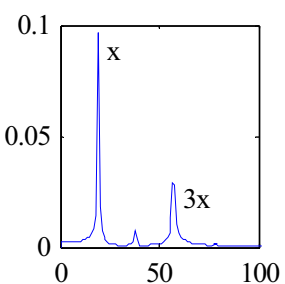

(d) $\Omega=1150 \mathrm{r} / \mathrm{min}$

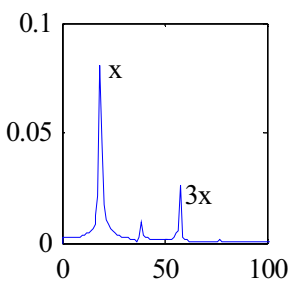

(e) $\Omega=1160 \mathrm{r} / \mathrm{min}$

Figure 7 Frequency spectra of the response in the horizontal direction during passage through the $1 / 3$ subcritical speed

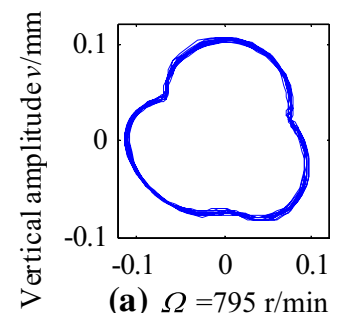

(a) $\Omega=795 \mathrm{r} / \mathrm{min}$

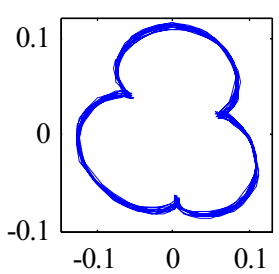

(b) $\Omega=825 \mathrm{r} / \mathrm{min}$

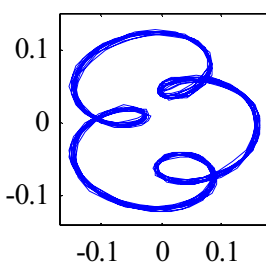

(c) $\Omega=850 \mathrm{r} / \mathrm{min}$

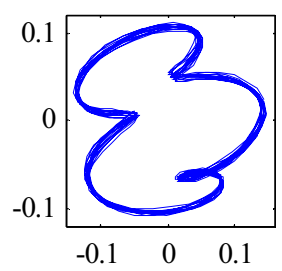

(d) $\Omega=858 \mathrm{r} / \mathrm{min}$

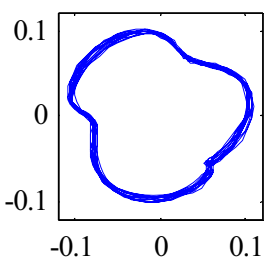

(e) $\Omega=885 \mathrm{r} / \mathrm{min}$

Horizontal amplitude $u / \mathrm{mm}$

Figure 8 Experimental whirl orbits of the cracked rotor during passage through the $1 / 4$ subcritical speed

are shown in Figure 9. It indicates that in this zone the 4X component exists and shows a similar variation pattern as the high-order frequency components in the $1 / 2$ and $1 / 3$ subcritical speed zones.

In Figure 10, four inner loops appear in the orbit when the rotating speed passes through the $1 / 5$ subcritical speed zone. However, compared to Figure 4, Figure 6 and
Figure 8, the size of the inner loop is smaller and the evolution process is not as obvious as in previous cases. The Fourier spectra shown in Figure 11 indicate that the high frequency $5 \mathrm{X}$ component does exists but is relatively weak which leads to the small inner loop.

From Figure 5, Figure 7, Figure 9 and Figure 11, it can be seen that near the subcritical speed, besides the 


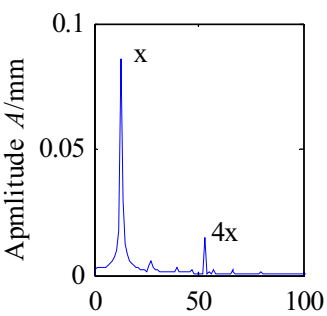

(a) $\Omega=795 \mathrm{r} / \mathrm{min}$

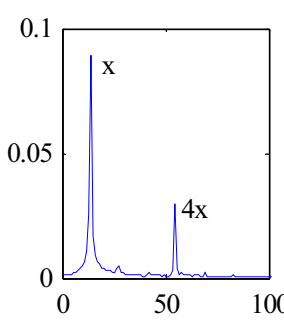

(b) $\Omega=825 \mathrm{r} / \mathrm{min}$

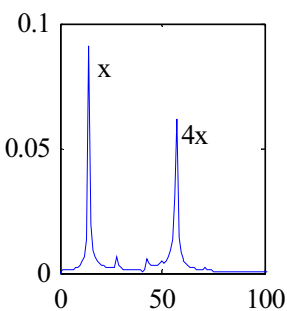

(c) $\Omega=850 \mathrm{r} / \mathrm{min}$

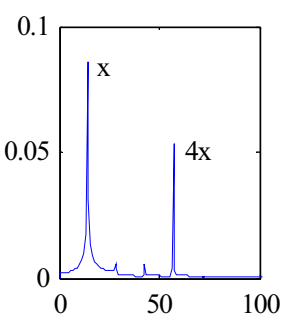

(d) $\Omega=859 \mathrm{r} / \mathrm{min}$

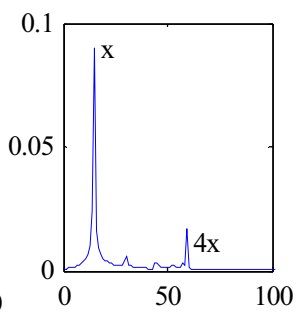

(e) $\Omega=885 \mathrm{r} / \mathrm{min}$

Frequency $f / \mathrm{Hz}$

Figure 10 Experimental whirl orbits of the cracked rotor during passage through the $1 / 5$ subcritical speed
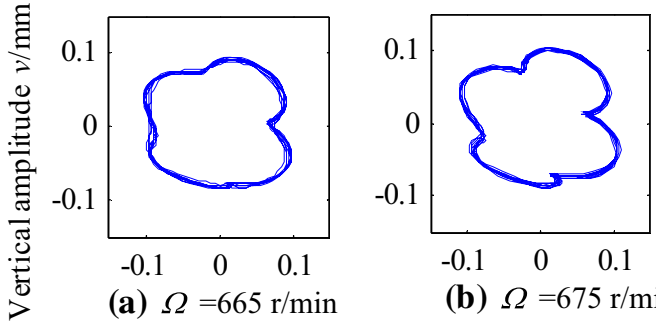

(b) $\Omega=675 \mathrm{r} / \mathrm{min}$

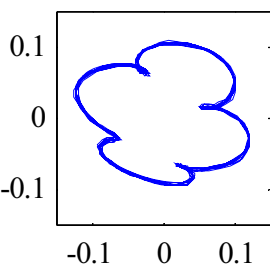

(c) $\Omega=680 \mathrm{r} / \mathrm{min}$

Horizontal amplitude $u / \mathrm{mm}$

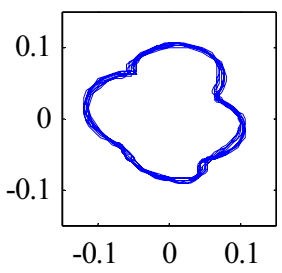

(d) $\Omega=685 \mathrm{r} / \mathrm{min}$
Figure 11 Frequency spectra of the response in the horizontal direction during passage through the $1 / 5$ subcritical speed

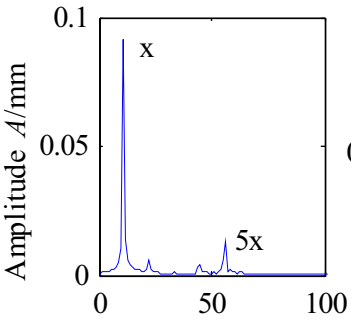

(a) $\Omega=665 \mathrm{r} / \mathrm{min}$

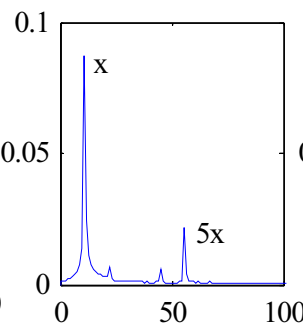

(b) $\Omega=675 \mathrm{r} / \mathrm{min}$

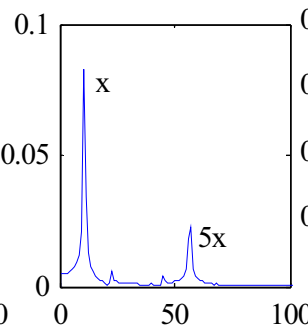

(c) $\Omega=680 \mathrm{r} / \mathrm{min}$

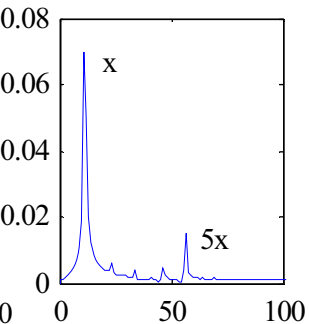

(d) $\Omega=685 \mathrm{r} / \mathrm{min}$

Frequency $f / \mathrm{Hz}$

basic frequency, the high frequency harmonic of the first critical speed is obvious which leads to the appearance of the typical orbits. When the rotating speed is in the lower subcritical speed zone, the corresponding high resonance frequency component is weaker. From Figures 4-11, we believe that the unique dynamic responses in the sub-critical speed zones have been systematically investigated and documented by the current set of experiments.

\section{Conclusions}

(1) In the experiment, typical inner loops appear when the cracked rotor passes the $1 / 5,1 / 4,1 / 3$ and $1 / 2$ subcritical speed zones, which well proves the theoretical findings in previous research.

(2) The FFT spectra indicates that in each subcritical speed region, higher frequency components always exist. In addition, during the passage, the closer the frequency to the center of the subcritical speed zone, the stronger the dominant component.

(3) Compared with previous experimental results, the investigation of the orbits and frequency spectra herein is more systematic and complete, which provides a crack diagnostics method for the health management in Industry 4.0 factories.

In future work, the experiment can be designed with multiple faults, such as the crack with bearing fatigue, oilfilm force, or rub-impact fault to study the influence of other faults on the dynamics of cracked rotor systems and the crack detection method in multi-fault cases.

Open Access This article is distributed under the terms of the Creative Commons Attribution 4.0 International License (http://crea tivecommons.org/licenses/by/4.0/), which permits unrestricted use, distribution, and reproduction in any medium, provided you give appropriate credit to the original author(s) and the source, provide a link to the Creative Commons license, and indicate if changes were made. 


\section{References}

1. J Qin, Y Liu, R GROSVENOR. A categorical framework of manufacturing for Industry 4.0 and beyond. Procedia CIRP, 2016, 52: 173-178.

2. S Y Wang, J F Wan, D Q ZHANG. Towards smart factory for industry 4.0: a self-organized multi-agent system with big data based feedback and coordination. Computer Networks, 2016, 101: $158-168$.

3. J Lee, B Bagheri, H A Kao. A cyber-physical systems architecture for industry 4.0-based manufacturing systems. Manufacturing Letters, 2015, 3: 18-23.

4. R Harrison, D Vera, B Ahmad. Engineering the smart factory. Chinese Journal of Mechanical Engineering, 2016, 29(6): 1046-1051.

5. A Radziwon, A Bilberg, BOGERS M, et al. The smart factory: exploring adaptive and flexible manufacturing solutions. Procedia Engineering, 2014, 69: 1184-1190.

6. J Lee. Smart factory systems. Informatik Spektrum, 2015, 38: 230-235.

7. S F Qin, V D Vab, E Chatzakis, et al. Exploring barriers and opportunities in adopting crowdsourcing based new product development in manufacturing SMEs. Chinese Journal of Mechanical Engineering, 2016, 29(6): 1052-1056.

8. A Hussein, K Cheng. Development of the supply chain oriented quality assurance system for aerospace manufacturing SMEs and its implementation perspectives. Chinese Journal of Mechanical Engineering, 2016, 29(6): 1067-1073.

9. S Weyer, M Schmitt, M Ohmer, et al. Towards industry $4.0-$ standardization as the crucial challenge for highly modular, multi-vendor production systems. IFAC-Papers Online, 2015, 48-3: 579-584.

10. J W Song, D Norman, T Nam, et al. Wireless device connection problems and design solutions. Chinese Journal of Mechanical Engineering, 2016, 29(6): 1145-1155.

11. B Bagheri, S Yang, H Kao, J Lee. Cyber-physical systems architecture for self-aware machines in Industry 4.0 environment. IFAC-Papers OnLine, 2015, 48-3: 1622-1627.

12. L Cheng, $\mathrm{N} \mathrm{Li}, \mathrm{X}$ Chen, et al. The influence of crack breathing and imbalance orientation angle on the characteristics of the critical speed of a cracked rotor. Journal of Sound and Vibration, 2011, 330: 2031-2048.

13. H Z Gao, L Liang, X G Chen, et al. Feature extraction and recognition for rolling element bearing fault utilizing short-time Fourier transform and non-negative matrix factorization. Chinese Journal of Mechanical Engineering, 2015, 28(1): 96-105.

14. S Singh, N Kumar. Combined rotor fault diagnosis in rotating machinery using empirical mode decomposition. Journal of Mechanical Science and Technology, 2014, 28 (12): 4869-4876.

15. C Kumar, V Rastogi. A brief review on dynamics of a cracked rotor. International Journal of Rotating Machinery, 2009, 2009(2): 1-6.

16. R T Liong, C Proppe. Application of the cohesive zone model for the evaluation of stiffness losses in a rotor with a transverse breathing crack. Journal of Sound and Vibration, 2013, 332: 2098-2110

17. J J Sinou, A W Lees. A non-linear study of a cracked rotor. European Journal of Mechanics A/Solids, 2007, 26: 152-170.

18. T R Babu, S Srikanth, A S Sekhar. Hilbert-Huang transform for detection and monitoring of crack in a transient rotor. Mechanical Systems and Signal Processing, 2008, 22: 905-914.
19. M A Al-Shudeifat, E A Butcher. New breathing functions for the transverse breathing crack of the cracked rotor system: Approach for critical and subcritical harmonic analysis. Journal of Sound and Vibration, 2011, 330:526-544.

20. M Silani, S Ziaei-rad, H Talebi. Vibration analysis of rotating systems with open and breathing Cracks. Applied Mathematical Modelling, 2013, 37: 9907-9921.

21. C Shravankumar, R Tiwari. Detection of a fatigue crack in a rotor system using full-spectrum based estimation. Sādhānā, 2016, 41(2): 239-251.

22. Z Y Lu, L Hou, Y S Chen. Nonlinear response analysis for a dualrotor system with a breathing transverse crack in the hollow shaft. Nonlinear Dynamics, 2016, 83: 169-185.

23. C Z Guo, M A Al-Shudeifat, J H Yan, et al. Application of empirical mode decomposition to a Jeffcott rotor with a breathing crack. Journal of Sound and Vibration, 2013, 332: 3881-3892.

24. M J Gomez, C Castejon, J C Garcia-Prada. Crack detection in rotating shafts based on $3 \mathrm{X}$ energy: analytical and experimental analyses. Mechanism and Machine Theory, 2016, 96: 94-106.

25. A K Darpe, K Gupta, A Chawla. Transient response and breathing behaviour of a cracked Jeffcott rotor. Journal of Sound and Vibration, 2004, 272: 207-243.

26. T Zhou, Z C Sun, J X Xu, et al. Experimental analysis of cracked rotor. Journal of Dynamic Systems, Measurement, and Control, 2005, 127: 313-320.

27. Z H Ren, S H Zhou, C H E, et al. Crack fault diagnosis of rotor systems using wavelet transforms. Computers and Electrical Engineering, 2015, 45: 33-41.

28. H B Dong, X F Chen, B Li, et al. Rotor crack detection based on high-precision modal parameter identification method and wavelet finite element model. Mechanical Systems and Signal Processing, 2009, 23: 869-883.

29. Y L Lin, F L Chu. Numerical and experimental investigations of flexural vibrations of a rotor system with transverse or slant crack. Journal of Sound and Vibration, 2009, 324: 107-125.

30. A A Mohammed, R D Neilson, W F Deans, et al. Crack detection in a rotating shaft using artificial neural networks and PSD characterization. Meccanica, 2014, 49: 255-266.

Chao-Zhong Guo, born in 1982, is currently an assistant professor at Harbin Institute of Technology, China. He received his $\mathrm{PhD}$ degree from Harbin Institute of Technology, China, in 2014. During 2010 to 2012, he studied in University of Illinois at Urbana-Champaign as a joint $\mathrm{PhD}$ candidate. His research interests include prognostics, rotor dynamics. Tel: +86-451-86414374; E-mail: cguo@hit.edu.cn

Ji-Hong Yan, born in 1972, is currently a professor at Harbin Institute of Technology, China. She received her $\mathrm{PhD}$ degree from Harbin Institute of Technology, China, in 1999. Her research interests include prognostics, sustainable manufacturing, and intelligent manufacturing. Tel: +86-451-86402972; E-mail: jyan@hit.edu.cn

Lawrence A. Bergman, is currently a professor at University of Illinois at Urbana-Champaign, USA. He received his $\mathrm{PhD}$ degree from Case Western Reserve University, USA, in 1980. His research interests include stochastic dynamics, linear and nonlinear structural dynamics and control, nonlinear system identification. Tel: +1-217333-4970; E-mail: lbergman@illinois.edu 